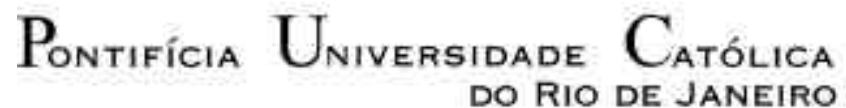

DO RIO DE JANEIRO

Roosevelt Fideles de Souza

\title{
UMA EXPERIÊNCIA EM EDUCAÇÃO AMBIENTAL: FORMAÇÃO DE VALORES SOCIOAMBIENTAIS
}

Dissertação de Mestrado

Dissertação apresentada como requisito parcial para obtenção do grau de Mestre pelo Programa de Pós-graduação em Serviço Social do Departamento de Serviço Social da PUC-Rio.

Orientador: Denise Pini Rosalem da Fonseca

Rio de Janeiro

Dezembro de 2003 


\title{
Pontifícia Universidade Católica \\ DO RIO DE JANEIRO
}

Roosevelt Fideles de Souza

\section{UMA EXPERIÊNCIA EM EDUCAÇÃO AMBIENTAL: FORMAÇÃO DE VALORES SOCIOAMBIENTAIS}

Dissertação apresentada como requisito parcial para obtenção do grau de Mestre pelo Programa de Pós-graduação em Serviço Social do Departamento de Serviço Social do Centro de Ciências Sociais da PUC-Rio. Aprovada pela Comissão Examinadora abaixo assinada.

\author{
Profa. Denise Pini Rosalem da Fonseca \\ Orientador \\ Departamento de Serviço Social - PUC-Rio
}

Profa. Maria Aparecida Barbosa Marques

Departamento de Serviço Social - PUC-Rio

Prof. Josafá Carlos de Siqueira SJ Departamento de Geografia e Meio Ambiente - PUC-Rio

Profa. Zélia Milanez de Lossio e Seiblitz Vice-Decana de Pós-Graduação do Centro de Ciências Sociais - PUC-Rio

Rio de Janeiro, 11 de agosto de 2003 
Todos os direitos reservados. È proibida a reprodução total ou parcial do trabalho sem autorização da universidade, do autor e do orientador.

\section{Roosevelt Fideles de Souza}

Graduou-se no grau de Bacharel e Licenciatura em Geografia e Meio / Ambiente e Licenciatura em Historia na PUC-Rio em 1998. Participou de diversos congressos na área de Geografia, Meio Ambiente e Botânica. É Coordenador do Projeto de Educação Ambiental com Crianças de Escolas Públicas no Núcleo Interdisciplinar de Meio Ambiente - NIMA-PUC-Rio. É Professor no Serviço Social da Industria - SESI na cidade do Rio de Janeiro. E é Professor estatutário da Secretária Estadual de Educação do Rio de Janeiro.

Ficha Catalográfica

Souza, Roosevelt Fideles de

Uma experiência em educação ambiental: formação de valores socioambientais / Roosevelt Fideles de Souza; orientador: Denise Pini Rosalem da Fonseca. Rio de Janeiro : PUC, Departamento de Serviço Social, 2003.

125 f. : il. ; $30 \mathrm{~cm}$

Dissertação (mestrado) - Pontifícia Universidade Católica do Rio de Janeiro, Departamento de Serviço social.

Inclui referências bibliográficas.

1. Serviço social - Teses. 2. Educação ambiental. 3. Questões sócio-administrativas. 4. Valores sócioambientais. I. Fonseca, Denise Pini Rosalem da. II. Pontifícia Universidade Católica do Rio de Janeiro. Departamento de Serviço Social. III. Título. 


\section{Agradecimentos}

A minha família, pelo apoio, carinho e compreensão durante a minha vida.

A professora Denise Pini Rosalem Fonseca, minha orientadora, por ter acreditado em minhas idéias e em meu trabalho, pela dedicação e interesse, apesar do pouco tempo de convívio nesta academia de ensino.

As diversas pessoas que tornaram essa dissertação possível, como o Vice-Reitor Comunitário professor Augusto Sampaio, que ainda no tempo em que estudava no curso de graduação no Departamento de Geografia e Meio Ambiente, prestou uma inesquecível e imprescindível ajuda.

Ao professor Josafá Carlos de Siqueira SJ, pelo profissionalismo, atenção, orientação e respeito durante toda a minha jornada na PUC-Rio.

Aos professores do Departamento de Serviço Social, cujas disciplinas oferecidas em muito ajudaram no desenvolvimento desta dissertação.

Ao Cláudio Santiago, funcionário do Departamento de História pela ajuda na infraestrutura da preparação desta dissertação.

Dedico em especial a três membros da minha família, em memória dos meus pais, Lêda Nassaro Fidélis e Raymundo Nascimento Souza e da minha avó Horminda da Conceição Nassaro Leandro.

E por fim, dedico também a todos os que não perderam as esperanças de se construir uma sociedade melhor, mesmo reconhecendo os limites individuais, buscam uma nova forma de ser existir no nosso Planeta Terra. 


\section{Resumo}

Souza, Roosevelt Fidelis de; Fonseca, Denise Pini Rosalem da. Uma experiência em Educação Ambiental: formação de valores socioambientais. Rio de Janeiro, 2003. 125 p. Dissertação de Mestrado - Departamento de Serviço Social, Pontifícia Universidade Católica do Rio de Janeiro.

Este estudo teve como motivação inicial a experiência profissional do autor, como educador e geógrafo, atuando na iniciativa denominada "Projeto de Educação Ambiental com Crianças de Escolas públicas", que vem sendo realizada no campus da Pontifícia Universidade Católica do Rio de Janeiro desde 1998. Este projeto foi desenvolvido pelo Núcleo Interdisciplinar de Meio Ambiente - NIMA/PUC-Rio, com o objetivo de integrar as escolas públicas com a Universidade, através de aulas de Educação Ambiental, tendo como meta a formação de valores ético-ambientais para o exercício da cidadania das futuras gerações. Baseado nesta experiência de projeto social, que visa atender às crianças mais carentes que estudam nas escolas públicas no bairro da Gávea e moradoras das comunidades carentes da Rocinha, Vidigal, Parque da Cidade e Cruzada São Sebastião, localizadas próximas ao campus da PUC-Rio, são apresentadas aqui as reflexões e potencialidades de transformação social do "Projeto de Educação Ambiental com Crianças de Escolas Públicas”.

A análise deste Projeto, enquanto um modelo que visa responder aos atuais apelos da recente Lei Federal de Educação Ambiental e da Lei Estadual, sobretudo no que se refere a sua dimensão não-formal, constitui o escopo desta dissertação. Em outras palavras, este trabalho avalia as ações e práticas educativas voltadas para a sensibilização da coletividade sobre as questões ambientais, com a participação e parceria de escolas, Universidade e empresas, e das transformações processadas com valores éticos presentes na relação do homem com o seu meio ambiente, através de um projeto de Educação Ambiental, realizado junto às crianças e adolescentes estudantes da rede pública de educação no Estado do Rio de Janeiro.

\section{Palavras-chave}

Educação Ambiental; questões sócio-ambientais; valores sócio-ambientais. 


\section{Abstract}

Souza, Roosevelt Fidelis de; Fonseca, Denise Pini Rosalem da. An experience on Environmental Education: building social-environmental values. Rio de Janeiro, 2003. 125 p. MSc. Dissertation - Departamento de Serviço Social, Pontifícia Universidade Católica do Rio de Janeiro.

This research was motivated by the author's professional experience, as a Geography teacher, working as a member of the team responsible for the "Project of Environmental Education for Public School Children", which has been taking place within the Pontifical Catholic University of Rio de Janeiro campus since 1998. This project was developed by the Interdisciplinary Center for the Environment NIMA/PUC-Rio to promote the integration of the public schools with the university, throughout Environmental Education classes. The goal of the project is to develop ethical-environmental values for the exercise of future generations citizenship. The purpose of this initiative is to serve the poor children, who attend classes of the public schools of Gávea, Rocinha, Vidigal, Parque da Cidade e Cruzada de São Sebastião neighborhoods, located near by PUC-Rio campus. Based on this experience, the author describes the perspectives for social change of the "Project of Environmental Education for Public School Children".

The core subject of this dissertation is an analysis of this project, taken as a model response to the determinations of the recent Federal and State Laws for environmental education, with emphasis on non-formal education. In other words, this essay describes the educational actions and practices designed to wake up collective sensibility towards environmental issues, relying on the partner ship established by schools with universities and companies. This dissertation is concerned with the ethical valves which comes out of the relation ship between mankind and its surrounding nature and the transformations that can be accomplished by an Environmental Education Project such as this one offered to the children of the public education system of the State of Rio de Janeiro.

\section{Keywords}

Environmental Education; Social environmental issues; Social environmental values. 


\section{Sumário}

1. Introdução

2. Educação Ambiental: questões de metodologia 12

2.1. Educação Ambiental e sua concepção 18

2.2. Educação Ambiental para a Sustentabilidade 20

2.3. Educação Ambiental Não-Formal 23

2.4. Educação Ambiental como tema transversal 25

2.5 O Serviço Social e o Meio Ambiente 26

3. Questões Sócio-Ambientais e Educação 32

3.1. Histórico da Educação Ambiental 35

3.2. Cronologia das iniciativas relativas à Educação Ambiental 38

4. Educação Ambiental e Políticas Públicas 55

4.1. Política Nacional de Educação Ambiental 56

4.2. I Conferência Nacional de Educação Ambiental 67

4.3. Programa Nacional de Educação Ambiental do MMA 69

4.4. A Construção social de novos valores éticos 72

4.5. Documentos produzidos no MEC 73

4.6. Carta Brasileira de Educação Ambiental 75

4.7. Parâmetros em Ação de Meio Ambiente 77

4.8. Documentos Nacionais 79

4.9. O que é a Agenda 21

4.10. A Agenda 21 Nacional - O Processo brasileiro 88

4.11. A Carta da Terra 90

4.12. A Educação Ambiental e as Organizações Não-Governamentais 92

4.13. Principais documentos internacionais com referências a Educação $\begin{array}{ll}\text { Ambiental } & 93\end{array}$

5. A transmissão de valores sócio-ambientais e sua importância no processo de conscientização e exercício da cidadania 
6. Conclusão 102

$\begin{array}{ll}\text { 6.1 Resultados do Projeto } & 106\end{array}$

$\begin{array}{lr}\text { 7. Referências bibliográficas } & 109\end{array}$

8. Anexos 114

8.1. Folha de freqüência 114

8.2. Fotos das aulas de Educação Ambiental no campus da PUC-Rio 115

8.3. Redações e desenhos realizados pelos alunos participantes 118 